\title{
Atheromas Feel the Pressure
}

\section{Biomechanical Stress and Atherosclerosis}

\author{
Amy L. Pyle, ${ }^{\star}$ and Pampee P. Young ${ }^{\star \ddagger}$ \\ From the Departments of Pathology," and Internal Medicine, ${ }^{\dagger}$ \\ Vanderbilt University Medical Center, Nashville; and the \\ Department of Pathology, ${ }^{\ddagger}$ Nashville Veterans Affairs Medical \\ Center, Nashville, Tennessee
}

\begin{abstract}
Atherosclerosis, a chronic vascular disease, is the underlying cause of over half the deaths in the United States each year. Variations in local vascular hemodynamics predispose select sites in the vasculature to atherosclerosis, and the atherosclerotic lesions, in turn alter the biomechanical functioning of the local microenvironment, the consequences of which are not well understood on a molecular level. Further progress in the field of atherosclerosis will require an understanding of the relationship between biomechanics, the tissue microenvironment, and the cellular and molecular response to these factors. This review summarizes this field, particularly within the context of the vascular smooth muscle cell. (Am J Patbol 2010, 177:4-9; DOI: 10.2353/ajpath.2010.090615)
\end{abstract}

Biomechanics play a vital role in vascular biology, affecting the cells of arteries and veins under both physiological and pathological conditions. While many studies have shown that the development of atherosclerosis is particularly associated with specific alterations of biomechanical forces, the effect of biomechanics on an established atheroma is less well studied. This minireview aims to describe the role of biomechanics in the vasculature, particularly in vascular smooth muscle cells (VSMCs) of large arteries, in normal and atherosclerotic conditions.

Two of the primary mechanical stimuli experienced by normal large arteries are shear stress and cyclic strain. ${ }^{1}$ By contrast, veins experience only very low levels of either. ${ }^{2}$ Shear stress is experienced by the endothelium as blood flows through the lumen. While endothelial cells are the primary sensors of shear stress, some stress may be relayed to the VSMCs by transmural transmission through the extracellular matrix $(E C M))^{3}$ Unlike shear stress, cyclic strain affects both endothelial cells and
VSMCs, as well as, though to a lesser degree, adventitial fibroblasts. ${ }^{4}$ The effects of cyclic strain on VSMCs have been the subject of much study in the recent decades, and many methods have been developed for exposing cells and tissues to cyclic strain both in vitro and ex vivo (an in depth discussion of the topic can be found in a review by Brown). ${ }^{5}$ While cyclic strain is a major determinant of normal VSMC physiology, it also plays a pivotal role in various pathologies, including hypertension, vein-graft intimal hyperplasia and failure, restenosis, and atherosclerosis. ${ }^{6}$

\section{VSMCs and Atherosclerosis}

Atherosclerosis, the underlying cause of most myocardial infarctions and strokes, is ultimately responsible for up to $50 \%$ of all deaths in the United States. ${ }^{7}$ In light of this, it is of great importance to understand atherosclerosis to improve detection and treatment of the disease. There are multiple factors affecting initiation and progression of the atherosclerotic lesion. Much of the existing research in the field has focused on the role of lipids and inflammation in atherosclerosis. Less well understood is the role of biomechanical forces, particularly in VSMCs. The underlying principles regarding the effect of biomechanics on atherosclerosis are emerging and these are briefly reviewed here.

Atherosclerosis occurs in large and medium-sized arteries and develops over time, starting with fatty streaks, progressing to intermediate lesions, and eventually proceeding to advanced and complicated lesions at risk of rupture (Figure 1). ${ }^{8-10}$ VSMC accumulation is a hallmark

Supported by a National Institutes of Health Training grant 5T32HL07751 (A.L.P.), a National Institutes of Health grant HL088424, a grant from the Department of Veterans Affairs 17-7488m, Pfizer Atorvastatin Research Award, and a grant from the American Heart Association (P.P.Y.).

Accepted for publication March 9, 2010.

CME Disclosure: None of the authors disclosed any relevant financial relationships.

Address reprint requests to Pampee Young, M.D., Ph.D., Vanderbilt University School of Medicine, Department of Pathology, $116121^{\text {st }}$ Ave. South. C2217A MCN, Nashville, TN 37232. E-mail: pampee.young@vanderbilt.edu. 

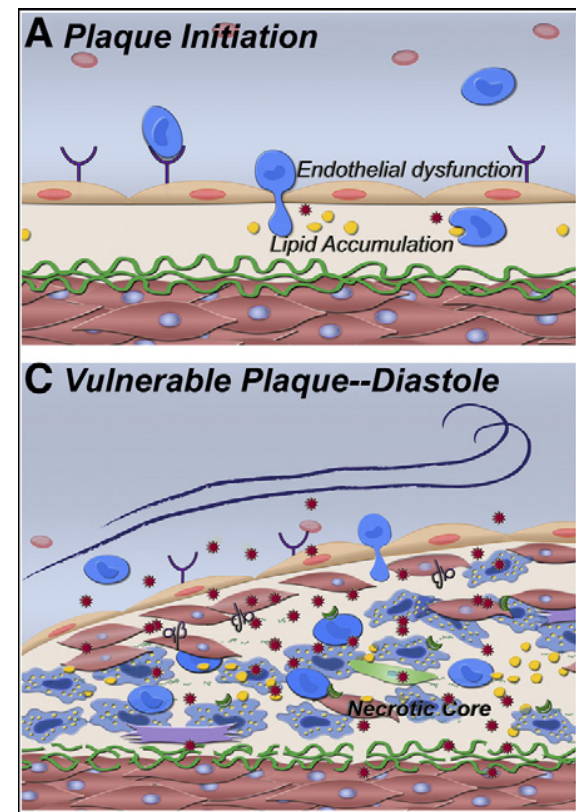

\section{Stable Plaque--Diastole}
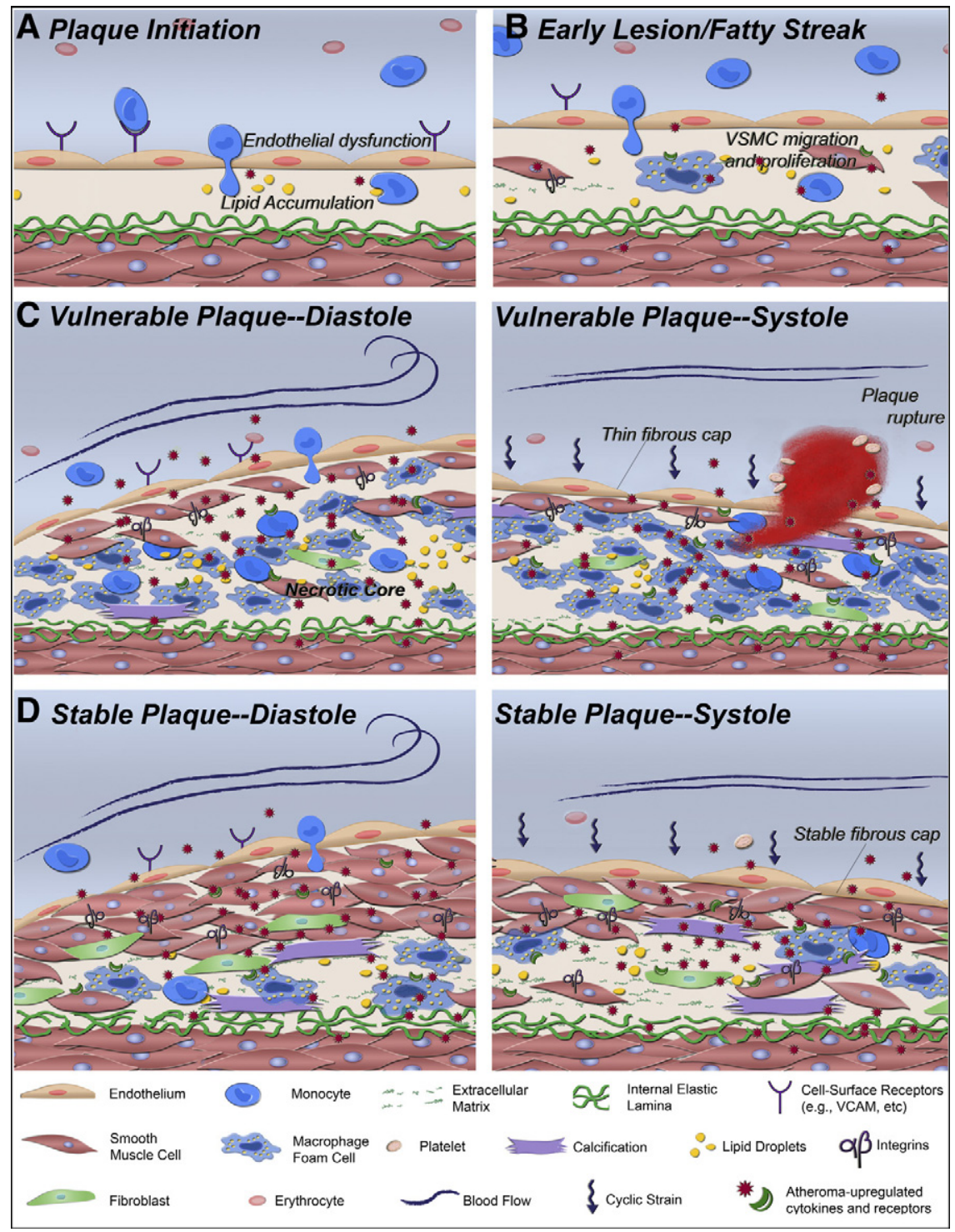

of moderate to advanced atheromas. Within the plaque, VSMCs act in diverse manners, primarily by modulating proliferation, inflammation, ECM modulation, and contraction. ${ }^{11}$ VSMC proliferation and hyperplasia within the plaque is largely mediated by platelet-derived growth factor and transforming growth factor $\beta$, which are both sensed and synthesized by the VSMCs. ${ }^{11}$ Early in plaque development, VSMCs secrete inflammatory mediators, such as monocyte chemoattractant protein 1, interleukins, and tumor necrosis factor $-\alpha .{ }^{11}$ These, along with surface expression of adhesion molecules such as intercellular adhesion molecule-1 and vascular cell adhesion molecule-1, promote macrophage infiltration and accumulation. ${ }^{11}$ It has been shown that VSMCs within an atherosclerotic plaque undergo phenotypic switching, moving from a more contractile to synthetic state. ${ }^{12}$ As such, VSMCs along with other local cells, such as macrophage foam cells, modify the local atherosclerotic milieu by synthesizing ECM molecules, primarily collagens I and III as well as matrix metalloproteinases, which degrade and remodel the ECM. This remodeling is critical in
Figure 1. Atherosclerotic progression is a complex process involving many cell types and the ECM. The normal human arterial intima is comprised of the endothelium, ECM (primarily collagens and elastin), and occasional VSMCs. The earliest events in atheroma formation are endothelial dysfunction and lipid accumulation in the arterial intima leading to macrophage infiltration and foam cell formation (A). Hallmarks of early lesions include migratory and proliferative VSMCs, as well (eg, integrins) as an up-regulation of cytokines and receptors that are unique to the atheroma microenvironment (B). The lesion progresses to a true atheroma and foam cells accumulate as VSMCs continue to proliferate and migrate, thereby increasing plaque size. Furthermore, VSMCs secrete collagen to generate a fibrous cap over the plaque $(\mathbf{C}, \mathbf{D})$. In advancing atherosclerosis, expansion of the plaque into the vessel lumen disrupts laminar blood flow. If the plaque is relatively VSMC-poor (due to apoptosis), especially with a lipid-rich necrotic core and thin fibrous cap, the plaque is vulnerable to fissure and rupture (C). Advanced plaques are subject to the dynamics of blood flow, from both shear and cyclic forces; as such plaques can compress during systole $(\mathbf{C}, \mathbf{D})$ However, if VSMCs are abundant within the lesion and actively secrete ECM to generate a thick fibrous cap, then the plaque will remain relatively stable, even in systole, and is unlikely to cause a clinically-recognizable event (D). determining the stability of the plaque. Indeed, increased MMP activity is thought to undermine plaque stability, thereby increasing the risk of rupture. ${ }^{13}$ Although they are in a primarily synthetic state, VSMCs within atheromas are still capable of responding to contractile stimuli, such as endothelin-1 and angiotensin II, which are present in the atherosclerotic plaque. ${ }^{14,15}$ Thus, the VSMC plays a vital role in atherosclerosis development and progression. Gaining further insight into these cells, particularly as they respond to a lesser-studied stimulant, biomechanical stress, will aid our understanding of atherosclerosis.

\section{Altered Biomechanics and Atherosclerosis}

It has long been known that biomechanical forces promote atherogenesis, specifically at curves, branch points, and bifurcations. ${ }^{16}$ Thus, atheromas most often arise in the branching coronary and carotid arteries, in the abdominal aorta at the branches for the abdominal 


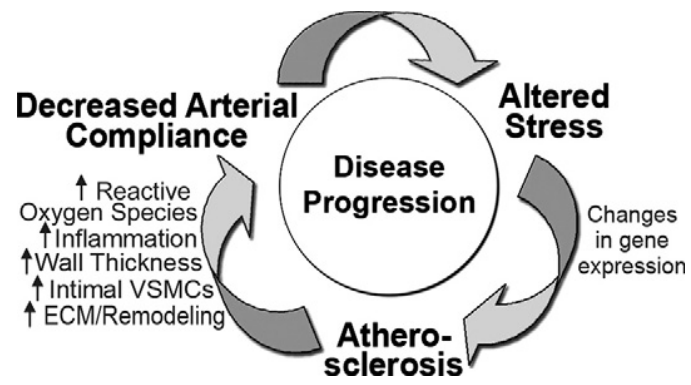

Figure 2. Biomechanic and atherosclerosis: A vicious cycle. Altered shear stress at branch point and curves is a well-known initiating step in atherosclerosis. The atherosclerotic plaque, in turn, promotes increased arterial compliance and distensibility as lipid, cells, and ECM accumulate in the vessel wall. As the vessel wall stiffens, it alters blood flow and changes the local hemodynamics. Altered stress then further promotes atherosclerosis through mechanosensing, resulting in changes in gene expression, thereby promoting increased plaque development.

arteries, and around the iliac bifurcation. ${ }^{17}$ Endothelial dysfunction occurs at regions where the blood flow is significantly disrupted and low; turbulent shear stress alters cellular behavior. Aspects of this state include a generalized inflammatory state of endothelial cells, which gives rise to generation of reactive oxygen species, altered surface markers, and increased lipid clearance into the intima. ${ }^{18}$ Furthermore, though it is less-well understood, the cyclic strain at these points is also significantly affected, with the direction and magnitude of stretch being different from areas of the arteries that are not atheroma-prone. Hence, these altered biomechanics that impact plaque initiation also impact VSMCs within an established plaque. ${ }^{19}$

An established atherosclerotic plaque itself is subject to alterations in biomechanical stress and such vessels experience distinct stresses as compared with those felt by healthy vessels. The most important cyclic strain is typically circumferential in the normal artery, but the cyclic strain field in a plaque is much more complex, involving extensional and shearing strains. Plaque compression during the high-pressure systolic phase of the cardiac cycle and rebound during diastole can now be directly assessed in vivo. The volume compression ratio (plaque volume at diastole minus plaque volume at systole divided by volume at diastole) demonstrates, in realtime, the dynamic and elastic nature of the atherosclerotic plaque, and has been proposed as a means for assessing risk of plaque rupture. ${ }^{20,21}$

Furthermore, studies have shown that biomechanical stress caused by altered flow not only leads to atherosclerosis, but atherosclerosis itself alters local biomechanics (Figure 2). ${ }^{19,22-24}$ Recently, sensitive technological innovations have become available, such as intravascular ultrasound, which revealed that even early atherosclerotic lesions significantly affect vessel compliance. ${ }^{19,22,23}$ One study has shown decreased arterial distensibility not only at the site of atherosclerosis, but also in proximal normal tissue, though not in distant normal artery. ${ }^{24}$

On the cellular level, there are many factors in the development of atherosclerosis that can affect vessel stiffness. For example, as the disease progresses, VSMC proliferation and inflammatory infiltrates (macrophages and lymphocytes) alter local cellular density. ECM synthesis and remodeling further promote local stiffening. Excess free cholesterol in the plaque can also be taken up into the plasma membranes of the resident cells, which may further alter membrane fluidity of the individual cells. ${ }^{25}$ Then, as the plaque progresses, interior necrosis and calcifications further decrease vessel compliance. ${ }^{11}$

Furthermore, generation of a fibrous cap plays an important role both in vessel stiffening and in plaque stability. The fibrous cap is a structure made up of VSMCs and collagen, which separates the lumen from the atheroma and stabilizes the plaque against rupture. ${ }^{26} \mathrm{~A}$ stable plaque is defined by a thick fibrous cap with extensive VSMC content, few macrophages, and a minimal necrotic core. On the other hand, an unstable, rupture-prone, or "vulnerable" plaque is defined by a thin fibrous cap, profound macrophage infiltration, low VSMC content, and a large lipid- and calcium-filled necrotic core. ${ }^{27}$ In the absence of a thick, stiff, protective top layer, the unstable plaque is prone to fracturing under the continuous shear and cyclic stresses. ${ }^{27}$

Decreased compliance in a diseased artery leads to disturbed wall motion and shear stress patterns as well as increasing turbulence, thereby further promoting plaque development (Figure 2). ${ }^{28}$ These changes in vessel compliance necessarily have an effect on the cells resident in the vessel, such as VSMCs. However, little is understood about the resulting molecular changes of VSMCs as they adapt to plaque biomechanics and their impact on plaque stability.

These changes in plaque stiffness are critical determinants in the propensity for plaque rupture. Moreover, the composition of each of the plaque constituents (eg, fibrous cap, necrotic core, etc) affects the overall plaque stability. For example, studies of the plaque fibrous cap have shown that VSMC-rich caps are 4 to 5 times stiffer than calcified caps, and 1 to 2 times stiffer than hypocellular caps. ${ }^{29}$ Moreover, it has been shown that the plaque shoulders are stiffer, and therefore subject to greater stress concentration, than the rest of the plaque. Consistent with this is the finding that the majority $(63 \%$ in one study of persons who died from coronary thrombosis) of ruptured plaques fissure at the shoulder. ${ }^{30}$

Thus, biomechanical alterations in the vasculature, predominantly in and around atherosclerotic plaques, are of significant biological and clinical interest. Of particular interest is how VSMCs, specifically those within the atherosclerotic microenvironment, sense and adapt to mechanical stress by altering gene regulation and cellular behavior in a way that could alter the plaque structure and stability. Therefore, the remainder of this document will focus on the mechanisms by which VSMCs sense stress and respond to it.

\section{Cellular Changes Resulting from Biomechanical Stress}

Many proteins have been implicated in mechanosensing by VSMCs, including the membrane oxidase $\mathrm{NADH} /$ $\mathrm{NADPH}$, stretch-activated ion channels, receptor tyrosine 
kinases, G-protein coupled receptors, integrins, and others. $^{31-33}$ However, within the context of vascular pathologies such as hypertension and atherosclerosis, certain mechanosensors are differentially regulated. For example, the angiotensin type I receptor, which has been shown to be a mechanosensor in VSMCs, is up-regulated in atherosclerosis. ${ }^{34}$ Furthermore, spontaneously hypertensive rats were shown to have more sensitive stretchactivated ion channels, compared with Wistar-Kyoto rats. ${ }^{35}$ Additionally, it has been shown that expression of integrin $\alpha_{1} \beta_{1}$ on VSMCs is limited to atheromas. ${ }^{31}$

In the context of the atherosclerotic plaque, VSMCs are surrounded by ECM, primarily type I collagen, and to a lesser extent elastin, vitronectin, and fibronectin. ${ }^{8}$ Cells can relate to and sense this environment through integrinECM interactions, thus making this interface an important focus of study. ${ }^{6}$ Hence the atheroma microenvironment generates a unique VSMC cellular phenotype (Figure 1). Importantly, extracellular stress and tension can be transmitted through the ECM via integrins to promote intracellular signaling events and alter gene regulation.

Similarly, the forces perceived are transferred to the VSMC cytoskeleton in ways that can influence VSMC biology. Transmission of these forces, particularly cyclic strain, in the context of the local environment produces a distinct set of responses in VSMCs, including altered cytoskeletal arrangement, ${ }^{36,37}$ changes in VSMC proliferation, ${ }^{38,39}$ apoptosis, ${ }^{2,40-42}$ and phenotype ${ }^{43,44}$; most of these responses are determined by altered gene expression. VSMCs modulate an array of genes in atherosclerosis, but only in the presence of the unique plaque microenvironment. For example, our lab and others have demonstrated expression of the type I collagen binding integrin $\alpha_{1} \beta_{1}$ by VSMCs within atheromas, and rarely by VSMCs of normal vasculature. ${ }^{31,45}$ This is the result of the influence of the atheroma microenvironment, which is rich in various cytokines such as transforming growth factor $\beta$, platelet-derived growth factor, monocyte chemoattractant protein 1, and others that modulate VSMC gene expression (Figure 1). ${ }^{11}$ The nature of this microenvironment causes biomechanical stress to differentially affect the VSMCs. For example, expression of $\alpha_{1} \beta_{1}$ integrin within VSMCs of an atheroma alters signal transduction downstream of cyclic strain and possibly other biomechanical forces as well matrix/cell interactions differentially within the cells comprising the atheroma resulting in unique gene expression. ${ }^{31}$ This demonstrates the need to recapitulate multiple features of the in vivo microenvironment when studying vascular biology in vitro. Not only should the cellular and ECM components be consistent with the physiological context, but the mechanical strains of the system should also be accounted for when working in vitro.

The primary manner in which physical changes arise following biomechanical stress is through modulation of gene transcription. For example, many groups have demonstrated upregulation of a variety of genes in VSMCs in response to cyclic strain including $\alpha$-actinin, extracellular matrix genes, cytoskeletal elements, integrins, monocyte chemoattractant protein 1, protease-activated receptor-1, syndecans 1,2 , and 4 , and many other genes. ${ }^{40,46-50}$
These changes in gene expression have a variety of effects on VSMCs, including changes in the cytoskeleton, apoptosis, proliferation, and phenotypic state.

In the artery wall, VSMCs are arranged in a helix around the artery and are orientated $50^{\circ}$ to $70^{\circ}$ relative to the axis of cyclic strain. A well-documented in vitro response of VSMCs to cyclic strain is the remodeling of the cytoskeleton such that the cells orient themselves perpendicular to the direction of stretch. ${ }^{51,52}$ Furthermore, cytoskeletal proteins themselves can respond to cyclic strain. Rat aortic VSMCs exposed to acute 15\% cyclic strain demonstrate translocation of zyxin from focal adhesions to the nucleus, where it affected expression of mechanosensitive genes. However, this was a transient effect; following long-term strain (6 hours), the majority of zyxin returned to the cytoplasm. ${ }^{53}$ While not a cytoskeletal element, the transcription factor Egr-1 relocated within the cell in response to stress as well. Egr-1 was not only increased in neonatal rat VSMCs exposed to cyclic strain, but was also shown to translocate to the nucleus in response to the strain. ${ }^{54}$

Modulation of apoptosis and proliferation has also been shown to be regulated by mechanosensing. VSMC apoptosis has various effects on the atherosclerotic plaque, and can affect plaque stability, calcification, and inflammation. ${ }^{41}$ Generally, cyclic strain increases VSMC apoptosis. Many groups have studied the mechanisms by which this occurs, with the goal of eventually reversing the effect, thereby promoting plaque stability. ${ }^{2,52,55,56}$ In general, changing the rate of apoptosis of VSMCs in an atheroma could be a potential method for regulating plaque stability. VSMC proliferation is a key step in atherogenesis, and a plaque with high VSMC content is generally more stable and, therefore, less likely to initiate a clinical event. Several reports suggest that cyclic strain promotes proliferation in VSMCs, whereas other work suggests that cyclic strain inhibits VSMC proliferation.

The study of VSMCs has revealed a great deal of information into the role of biomechanical stress, particularly cyclic strain, in normal smooth muscle cell biology. It also opens a window into understanding the role of VSMCs in the pathogenesis of mechano-sensitive diseases such as atherosclerosis. These have been extensively addressed in many excellent reviews, and the reader should refer to these for more information. ${ }^{33,57-59}$

\section{Perspectives}

The study of the effects of biomechanics on the vasculature, particularly in cases of vascular pathology, is an area still ripe for exploration. The molecular changes arising from biomechanics on VSMCs within an established atheroma remain largely unknown, particularly as the local microenvironment of the plaque changes throughout plaque development and progression. The atherosclerotic plaque has a unique mélange of ECM, cells, cytokines and other inflammatory mediators, dead and dying cells, and lipids. So complex is this microenvironment that it cannot reasonably be recapitulated in completion in vitro. A better understanding of the VSMC 
response to biomechanical stress within the atherosclerotic milieu may require consideration of their local context. Such insights will promote our understanding of plaque stability and rupture, and lead to the development of better detection and treatment options for atherosclerosis.

\section{Acknowledgments}

We thank Dr. Jay Jerome and Dr. Samuel Santoro for their critical reading of this manuscript.

\section{References}

1. Vanepps JS, Vorp DA: Mechano-pathobiology of atherogenesis: a review. J Surg Res 2007, 142:202-217

2. Mayr M, Hu Y, Hainaut $H, X u$ Q: Mechanical stress-induced DNA damage and rac-p38MAPK signal pathways mediate p53-dependent apoptosis in vascular smooth muscle cells. FASEB J 2002, 16:1423-1425

3. Stegemann JP, Hong H, Nerem RM: Mechanical, biochemical, and extracellular matrix effects on vascular smooth muscle cell phenotype. J Appl Physiol 2005, 98:2321-2327

4. Li L, Couse TL, Deleon H, Xu CP, Wilcox JN, Chaikof EL: Regulation of syndecan-4 expression with mechanical stress during the development of angioplasty-induced intimal thickening. J Vasc Surg 2002, 36:361-370

5. Brown TD: Techniques for mechanical stimulation of cells in vitro: a review. J Biomech 2000, 33:3-14

6. Li C, Xu Q: Mechanical stress-initiated signal transductions in vascular smooth muscle cells. Cell Signal 2000, 12:435-445

7. Thom T, Haase N, Rosamond W, Howard VJ, Rumsfeld J, Manolio T, Zheng Z-J, Flegal K, O'Donnell C, Kittner S, Lloyd-Jones D, Goff DC $\mathrm{Jr}$, Hong $\mathrm{Y}$, Members of the Statistics Committee and Stroke Statistics Subcommittee, Adams R, Friday G, Furie K, Gorelick P, Kissela B, Marler J, Meigs J, Roger V, Sidney S, Sorlie P, Steinberger J, Wasserthiel-Smoller S, Wilson M, Wolf P: Heart Disease and Stroke Statistics-2006 Update: A Report From the American Heart Association Statistics Committee and Stroke Statistics Subcommittee, 1161/ CIRCULATIONAHA. 105.171600. Circulation 2006, 113:e85-e151

8. Stary HC, Blankenhorn DH, Chandler AB, Glagov S, Insull W Jr, Richardson M, Rosenfeld ME, Schaffer SA, Schwartz CJ, Wagner WD, Wissler RW: A definition of the intima of human arteries and of its atherosclerosis-prone regions. A report from the Committee on Vascular Lesions of the Council on Arteriosclerosis, American Heart Association. Arterioscler Thromb 1992, 12:120-134

9. Stary HC, Chandler AB, Dinsmore RE, Fuster V, Glagov S, Insull W Jr, Rosenfeld ME, Schwartz CJ, Wagner WD, Wissler RW: A definition of advanced types of atherosclerotic lesions and a histological classification of atherosclerosis. A report from the Committee on Vascular Lesions of the Council on Arteriosclerosis, American Heart Association. Arterioscler Thromb Vasc Biol 1995, 15:1512-1531

10. Stary HC, Chandler AB, Glagov S, Guyton JR, Insull W Jr, Rosenfeld ME, Schaffer SA, Schwartz CJ, Wagner WD, Wissler RW: A definition of initial, fatty streak, and intermediate lesions of atherosclerosis. A report from the Committee on Vascular Lesions of the Council on Arteriosclerosis, American Heart Association. Circulation 1994, 89:2462-2478

11. Dzau VJ, Braun-Dullaeus RC, Sedding DG: Vascular proliferation and atherosclerosis: new perspectives and therapeutic strategies. Nat Med 2002, 8:1249-1256

12. Forrest S, McNamara C: Id family of transcription factors and vascular lesion formation. Arterioscler Thromb Vasc Biol 2004, 24:2014-2020

13. Johnson JL: Matrix metalloproteinases: influence on smooth muscle cells and atherosclerotic plaque stability. Expert Rev Cardiovasc Ther 2007, 5:265-282

14. Hahn AW, Resink TJ, Scott-Burden T, Powell J, Dohi Y, Buhler FR: Stimulation of endothelin mRNA and secretion in rat vascular smooth muscle cells: a novel autocrine function. Cell Regul 1990, 1:649-659
15. Sendra J, Llorente-Cortes V, Costales P, Huesca-Gomez C, Badimon L: Angiotensin II upregulates LDL receptor-related protein (LRP1) expression in the vascular wall: a new pro-atherogenic mechanism of hypertension. Cardiovasc Res 2008, 78:581-589

16. Davies PF, Polacek DC, Handen JS, Helmke BP, DePaola N: A spatial approach to transcriptional profiling: mechanotransduction and the focal origin of atherosclerosis. Trends Biotechnol 1999, 17:347-351

17. Frangos SG, Gahtan V, Sumpio B: Localization of atherosclerosis: role of hemodynamics. Arch Surg 1999, 134:1142-1149

18. Gimbrone MA Jr, Topper JN, Nagel T, Anderson KR, Garcia-Cardena G: Endothelial dysfunction, hemodynamic forces, and atherogenesis. Ann NY Acad Sci 2000, 902:230-239, discussion 239-240

19. Chatzizisis YS, Giannoglou GD: Coronary hemodynamics and atherosclerotic wall stiffness: a vicious cycle. Med Hypotheses 2007, 69:349-355

20. Zhang PF, Su HJ, Yao GH, Wu W, Zhang M, Liu CX, Jiang H, Ding SF, Zhang C, Zhao YX, Zhang Y: Plaque volume compression ratio, a novel biomechanical index, is independently associated with ischemic cerebrovascular events. J Hypertens 2009, 27:348-356

21. Bardelli M: Ultrasonographic investigation of the mechanics of vulnerable atherosclerotic plaques: significance of the volume strain. $J$ Hypertens 2009, 27:219-220

22. Hong MK, Vossoughi J, Mintz GS, Kauffman RD, Hoyt RF Jr, Cornhill JF, Herderick EE, Leon MB, Hoeg JM: Altered compliance and residual strain precede angiographically detectable early atherosclerosis in low-density lipoprotein receptor deficiency. Arterioscler Thromb Vasc Biol 1997, 17:2209-2217

23. Dart AM, Kingwell BA: Pulse pressure-a review of mechanisms and clinical relevance. J Am Coll Cardiol 2001, 37:975-984

24. Giannattasio C, Failla M, Emanuelli G, Grappiolo A, Boffi L, Corsi D, Mancia G: Local effects of atherosclerotic plaque on arterial distensibility. Hypertension 2001, 38:1177-1180

25. Small DM, Shipley GG: Physical-chemical basis of lipid deposition in atherosclerosis. Science 1974, 185:222-229

26. Braganza DM, Bennett MR: New insights into atherosclerotic plaque rupture. Postgrad Med J 2001, 77:94-98

27. Mehta AS: Unstable or high risk plaque: how do we approach it. MJAFI 2006, 62:2-7

28. Li MX, Beech-Brandt JJ, John LR, Hoskins PR, Easson WJ: Numerical analysis of pulsatile blood flow and vessel wall mechanics in different degrees of stenoses. J Biomech 2007, 40:3715-3724

29. Lee RT, Grodzinsky AJ, Frank EH, Kamm RD, Schoen FJ: Structuredependent dynamic mechanical behavior of fibrous caps from human atherosclerotic plaques. Circulation 1991, 83:1764-1770

30. Richardson PD, Davies MJ, Born GV: Influence of plaque configuration and stress distribution on fissuring of coronary atherosclerotic plaques. Lancet 1989, 2:941-944

31. Pyle AL, Atkinson JB, Pozzi A, Reese J, Eckes B, Davidson JM, Crimmins DL, Young PP: Regulation of the atheroma-enriched protein. SPRR3, in vascular smooth muscle cells through cyclic strain is dependent on integrin alpha1beta1/collagen interaction. Am J Pathol 2008, 173:1577-1588

32. Hu Y, Bock G, Wick G, Xu Q: Activation of PDGF receptor alpha in vascular smooth muscle cells by mechanical stress. FASEB J 1998, 12:1135-1142

33. Kakisis JD, Liapis CD, Sumpio BE: Effects of cyclic strain on vascular cells. Endothelium 2004, 11:17-28

34. Hu C, Dandapat A, Chen J, Liu Y, Hermonat PL, Carey RM, Mehta JL: Over-expression of angiotensin II type 2 receptor (agtr2) reduces atherogenesis and modulates LOX-1, endothelial nitric oxide synthase and heme-oxygenase-1 expression. Atherosclerosis 2008, 199:288-294

35. Ohya $Y$, Adachi N, Nakamura Y, Setoguchi M, Abe I, Fujishima M: Stretch-activated channels in arterial smooth muscle of genetic hypertensive rats. Hypertension 1998, 31:254-258

36. Standley PR, Cammarata A, Nolan BP, Purgason CT, Stanley MA: Cyclic stretch induces vascular smooth muscle cell alignment via NO signaling. Am J Physiol Heart Circ Physiol 2002, 283:H1907-H1914

37. Chen Q, Li W, Quan Z, Sumpio BE: Modulation of vascular smooth muscle cell alignment by cyclic strain is dependent on reactive oxygen species and P38 mitogen-activated protein kinase. J Vasc Surg 2003, 37:660-668

38. Standley PR, Obards TJ, Martina CL: Cyclic stretch regulates auto- 
crine IGF-I in vascular smooth muscle cells: implications in vascular hyperplasia. Am J Physiol Endocrinol Metab 1999, 276:E697-E705

39. Wilson E, Mai Q, Sudhir K, Weiss RH, Ives HE: Mechanical strain induces growth of vascular smooth muscle cells via autocrine action of PDGF. J Cell Biol 1993, 123:741-747

40. Clarke M, Bennett M: The emerging role of vascular smooth muscle cell apoptosis in atherosclerosis and plaque stability. Am J Nephrol 2006, 26:531-535

41. Mayr M, Li C, Zou Y, Huemer U, Hu Y, Xu Q: Biomechanical stressinduced apoptosis in vein grafts involves $\mathrm{p} 38$ mitogen-activated protein kinases. FASEB J 2000, 14:261-270

42. Wernig F, Mayr M, Xu Q: Mechanical stretch-induced apoptosis in smooth muscle cells is mediated by beta1-integrin signaling pathways. Hypertension 2003, 41:903-911

43. Tock J, Van Putten V, Stenmark KR, Nemenoff RA: Induction of SM-alpha-actin expression by mechanical strain in adult vascular smooth muscle cells is mediated through activation of JNK and p38 MAP kinase. Biochem Biophys Res Commun 2003, 301:1116-1121

44. Qu MJ, Liu B, Wang HQ, Yan ZQ, Shen BR, Jiang ZL: Frequencydependent phenotype modulation of vascular smooth muscle cells under cyclic mechanical strain. J Vasc Res 2007, 44:345-353

45. Skinner MP, Raines EW, Ross R: Dynamic expression of alpha 1 beta 1 and alpha 2 beta 1 integrin receptors by human vascular smooth muscle cells. Alpha 2 beta 1 integrin is required for chemotaxis across type I collagen-coated membranes. Am J Pathol 1994, 145:1070-1081

46. Jiang MJ, Yu YJ, Chen YL, Lee YM, Hung LS: Cyclic strain stimulates monocyte chemotactic protein-1 mRNA expression in smooth muscle cells. J Cell Biochem 1999, 76:303-310

47. Nguyen KT, Frye SR, Eskin SG, Patterson C, Runge MS, McIntire LV: Cyclic strain increases protease-activated receptor-1 expression in vascular smooth muscle cells. Hypertension 2001, 38:1038-1043

48. Smith JD, Davies N, Willis AI, Sumpio BE, Zilla P: Cyclic stretch induces the expression of vascular endothelial growth factor in vascular smooth muscle cells. Endothelium 2001, 8:41-48

49. D'Addario M, Arora PD, Fan J, Ganss B, Ellen RP, McCulloch CAG:
Cytoprotection against mechanical forces delivered through beta 1 integrins requires induction of filamin A. 1074/jbc.M102715200. J Biol Chem 2001, 276:31969-31977

50. Sakamoto H, Aikawa M, Hill CC, Weiss D, Taylor WR, Libby P, Lee RT: Biomechanical strain induces class a scavenger receptor expression in human monocyte/macrophages and THP-1 cells: a potential mechanism of increased atherosclerosis in hypertension. Circulation 2001, 104:109-114

51. Shirinsky VP, Antonov AS, Birukov KG, Sobolevsky AV, Romanov YA, Kabaeva NV, Antonova GN, Smirnov VN: Mechano-chemical control of human endothelium orientation and size. J Cell Biol 1989, 109:331-339

52. Chapman GB, Durante W, Hellums JD, Schafer Al: Physiological cyclic stretch causes cell cycle arrest in cultured vascular smooth muscle cells. Am J Physiol Heart Circ Physiol 2000, 278:H748-H754

53. Cattaruzza M, Lattrich $\mathrm{C}$, Hecker M: Focal adhesion protein zyxin is a mechanosensitive modulator of gene expression in vascular smooth muscle cells. Hypertension 2004, 43:726-730

54. Morawietz H, Ma YH, Vives F, Wilson E, Sukhatme VP, Holtz J, Ives $\mathrm{HE}$ : Rapid induction and translocation of Egr-1 in response to mechanical strain in vascular smooth muscle cells. Circ Res 1999, 84:678-687

55. Su BY, Shontz KM, Flavahan NA, Nowicki PT: The effect of phenotype on mechanical stretch-induced vascular smooth muscle cell apoptosis. J Vasc Res 2006, 43:229-237

56. Sedding DG, Homann M, Seay U, Tillmanns H, Preissner KT, BraunDullaeus RC: Calpain counteracts mechanosensitive apoptosis of vascular smooth muscle cells in vitro and in vivo. FASEB J 2008, 22:579-589

57. Xu Q: Biomechanical-stress-induced signaling and gene expression in the development of arteriosclerosis. Trends Cardiovasc Med 2000, 10:35-41

58. Lehoux S, Tedgui A: Cellular mechanics and gene expression in blood vessels. J Biomech 2003, 36:631-643

59. Williams B: Mechanical influences on vascular smooth muscle cell function. J Hypertens 1998, 16:1921-1929 